\title{
Methodological Approach of Decision Support for the Development Choices of an Abandoned Quarry (The Landfill of Mohammedia-Morocco)
}

\author{
Nawal Ezzirari*, Lahcen Bahi \\ Laboratory of Geotechnics, Applied Geophysics, Geology of Engineers and Environment, Engineers’ Mohammedia School, \\ Mohammed V-Agdal University, Rabat, Morocco \\ Email: *nezzirari@gmail.com
}

Received May 11, 2013; revised June 11, 2013; accepted June 19, 2013

Copyright (C) 2013 Nawal Ezzirari, Lahcen Bahi. This is an open access article distributed under the Creative Commons Attribution License, which permits unrestricted use, distribution, and reproduction in any medium, provided the original work is properly cited.

\begin{abstract}
The principal component analysis of the landfill of Mohammedia, was carried out by monitoring and spatiotemporal analysis of a number of physical and chemical tracers (temperature, $\mathrm{pH}$, salinity, conductivity, dissolved oxygen, suspended solids, TOC and metal) of superficial waters during the years 2010-2012. It has, on the one hand, to evaluate several options in situations where no possibility is perfect, and secondly, to visualize the distribution of different individuals (wells), which gave an idea of their similarity relative the measured variables revealed two major groups: The group I is close to the proximal region of the river and landfill and submitted to direct influences of the latter and the group II, with transitional character between wells in Group I, which is characterized by a relatively high TOC showing a deteriorated water quality. And for the potential damage caused by the landfill of the waters of river El Maleh, the identification of suitable rehabilitation plan for this landfill becomes a necessity.
\end{abstract}

Keywords: Landfill; Wells; Analyse in Major Composantes; River El Maleh; Correlation

\section{Introduction}

The analysis multicriterion is a decision-making tool developed to solve complex problems which include qualitative and/or quantitative aspects in a decision-making. The choice of a site of arrangement of a quarry requires the use of an analysis of the spatial decision multicriterion [1].

The potential advantage of an approach based on Analyse in major composantes AMC for choosing type of rehabilitation approach is explained by the fact that it not only reduces the time and cost of the selection of the models of rehabilitation, but allows to evaluate several options in situations where no opportunity is perfect.

So, the AMC can also explore a set of observations collected in the form of a data table showing for each statistical unit observed values of a number of quantitative variables [2].

In addition, it allows to combine the economic, technological, environmental and social design for the importance of various criteria.

*Corresponding author.

\section{Materiels and Methods}

\subsection{Study Site}

The quarry of clay is situated near the river el Maleh, in the city of Mohammedia ( $\left.33^{\circ} 33^{\prime \prime} \mathrm{N} ; 7^{\circ} 23^{\prime \prime} \mathrm{W}\right)$, city of Moroccan Atlantic coast $65 \mathrm{~km}$ south of Rabat and $20 \mathrm{~km}$ north of Casablanca [3].

\subsection{Choice of Stations}

Five stations of sampling are distributed on the landfill were chosen so that they are representative, accessible, witnesses of the actual characteristics of these waters taken from wells at the various sites explored and to determine their overall physical and chemical processes defining the problem of contamination by the leaden and chromium [2,4]. Les échantillons d" eau de surface ont été prélevés à l" aide de flacons en polyéthylène de 250 $\mathrm{ml}$, previously washed in the distilled water and transported in portable ice boxes $\left(+4^{\circ} \mathrm{C}\right)$.

The physico-chemical determinism water of the landfill and river el Maleh has been made by the analysis of 16 physical and chemical parameters of the water at the 
five stations. Five of these variables were measured in the ground: temperature, $\mathrm{pH}$, salinity, conductivity and dissolved oxygen. The biological oxygen demand, chimical oxygen demande, nitrates, metallic $\mathrm{Cr}, \mathrm{Fe}, \mathrm{Zn}, \mathrm{Cd}, \mathrm{Cu}$ and $\mathrm{Pb}$ analysis, material suspended and the total organic carbon (TOC), were measured in the laboratory. The spatial evolution of the average values of the three years 2010, 2011 and 2012 of these parameters are shown in Tables 1 and 2.

\subsection{Analyse in Major Composantes AMC}

The methodology adopted for the realization of this analysis passed by the following stages $[5,6]$ :
- A preliminary analysis concerning the modalities of the decision and the consequences which it will be necessary to take into account to guide the choice $[7,8]$;

- An interpretation of how effectively the problem of decision support and the choice of an appropriate method to inform the decision;

- Implementation of this method, that is to say the collection of definitive data, performing calculations and interpretation of results [9].

\section{Results and Discussion}

The principal component analysis allowed us to perform linear transformations of a large number of inter-correla-

Table 1. Spatial Evolution of average values of the three years 2010, 2011 and 2012 for these parameters.

\begin{tabular}{|c|c|c|c|c|c|c|c|c|c|c|c|c|c|c|c|c|}
\hline $\begin{array}{l}\text { Sampling } \\
\text { station }\end{array}$ & Te & PH & Ce & Sa & $\mathrm{NO}_{3}$ & COD & OD & MES & TOC & BOD5 & $\mathbf{F e}$ & Zn & $\mathbf{C u}$ & $\mathbf{P b}$ & $\mathrm{Cr}$ & Cd \\
\hline Station (S1) & 23.17 & 3.52 & 41.19 & 26 & 5.63 & 23.29 & 1.49 & 71.58 & 14.46 & 7.73 & 28.52 & 129.36 & 14.63 & 70.13 & 64.24 & 0.91 \\
\hline Station (S2) & 23 & 3.90 & 43.49 & 30 & 4.54 & 20.87 & 2.33 & 65.52 & 8.67 & 7.51 & 28.51 & 130.13 & 14.04 & 50.78 & 63.18 & 1.09 \\
\hline Station (S3) & 23.5 & 3.80 & 28.35 & 8 & 3.83 & 18.42 & 3.48 & 50.29 & 7.43 & 7.05 & 23.07 & 109.78 & 13.50 & 21.87 & 59.37 & 1.08 \\
\hline Station (S5) & 21.09 & 7.16 & 4.60 & 5 & 2.58 & 16.13 & 9.02 & 18.55 & 12.45 & 5.68 & 20.29 & 105.80 & 11.03 & 25.88 & 45.29 & 1.18 \\
\hline
\end{tabular}

Te: temperature, pH: hydrogen potential, Sa: salinity, Ce: conductivity, OD: dissolved oxygen, BOD5: biological oxygen demand, COD: chimical oxygen demande, MES: material suspended, TOC: total organic carbon, Cr: Chrome, Fe: Fer, Zn: Zinc, Cd: Cadimium, Cu: Cuivre and Pb: Plomb.

Table 2. Descriptive statistics of the analyzed parametres.

\begin{tabular}{cccccccc}
\hline Variable & Observations & Obs. with missing data & Obs. without missing & Minimum & Maximum & Average & Standard deviation \\
\hline Te $\left({ }^{\circ} \mathbf{C}\right)$ & 5 & 0 & 5 & 21.090 & 23.500 & 22.562 & 0.984 \\
Hydrogen potential & 5 & 0 & 5 & 3.519 & 7.161 & 4.855 & 1.597 \\
Conductivity mS/cm & 5 & 0 & 5 & 3.105 & 43.494 & 24.150 & 19.412 \\
Salinity g/l & 5 & 0 & 5 & 3.105 & 29.825 & 14.182 & 12.574 \\
NO $_{3}$ mg/l & 5 & 0 & 5 & 2.456 & 5.629 & 3.806 & 1.340 \\
COD mg/l & 5 & 0 & 5 & 16.133 & 23.289 & 18.979 & 3.097 \\
OD mg/l & 5 & 0 & 5 & 1.488 & 9.022 & 4.568 & 3.136 \\
MES (mg/l) & 5 & 5 & 18.547 & 71.580 & 47.101 & 22.755 \\
TOC mg/l & 5 & 0 & 5 & 7.430 & 14.459 & 10.553 & 2.863 \\
BOD5 mg/l & 5 & 0 & 5 & 5.469 & 7.732 & 6.688 & 1.047 \\
Fe & 5 & 0 & 5 & 20.290 & 28.520 & 25.400 & 3.620 \\
Zn & 5 & 0 & 5 & 102.000 & 130.130 & 115.414 & 13.371 \\
Cu & 5 & 0 & 5 & 9.070 & 14.630 & 12.454 & 2.336 \\
Pb & 5 & 0 & 5 & 21.870 & 70.130 & 39.778 & 20.293 \\
Cr & 5 & 0 & 5 & 45.290 & 77.230 & 61.862 & 11.450 \\
Cd & 5 & 0 & 0.280 & 1.180 & 0.908 & 0.364 \\
\hline
\end{tabular}

Te: temperature, pH: hydrogen potential, Sa: salinity, Ce: conductivity, OD: dissolved oxygen, BOD5: biological oxygen demand, COD: chimical oxygen demande, MES: material suspended, TOC: total organic carbon, Cr: Chrome, Fe: Fer, Zn: Zinc, Cd: Cadimium, Cu: Cuivre and Pb: Plomb. 
ted variables in order to obtain a relatively small number of uncorrelated components [10,11].

This approach has facilitated our analysis by grouping the data into smaller sets and to eliminate the problems of multicollinearity between variables [12,13]. Projections of physico-chemical parameters and wells obtained are presented in Figures 1 and 2.

The contribution to the total variability in the first three axes from the AMC performed on the values of the sixteen parameters obtained for the five wells is $97 \%$, $69 \%$ for axis 1, 16\% for the axis 2 and $11 \%$ for Axis 3 .

Axis 1 is essentially characterized in the positive direction by three parameters that are strongly correlated: COD, Ce, Te, Sa, Mes, TOC, BOD5, Fe, Zn, Cu, Pb, Cr and $\mathrm{Cd}$ This axis defines an increasing gradient of the content of these elements on the left of the axis towards the right side. It can be called as an area of mineralization and rich in organic matter. By against axis 2 in the negative direction opposes the variables mentioned above $\mathrm{PH}$ and dissolve oxygen $[14,15]$.

The projection of individuals on both factorial F1-F2 and F2-F3 shows a wide dispersion of wells showing
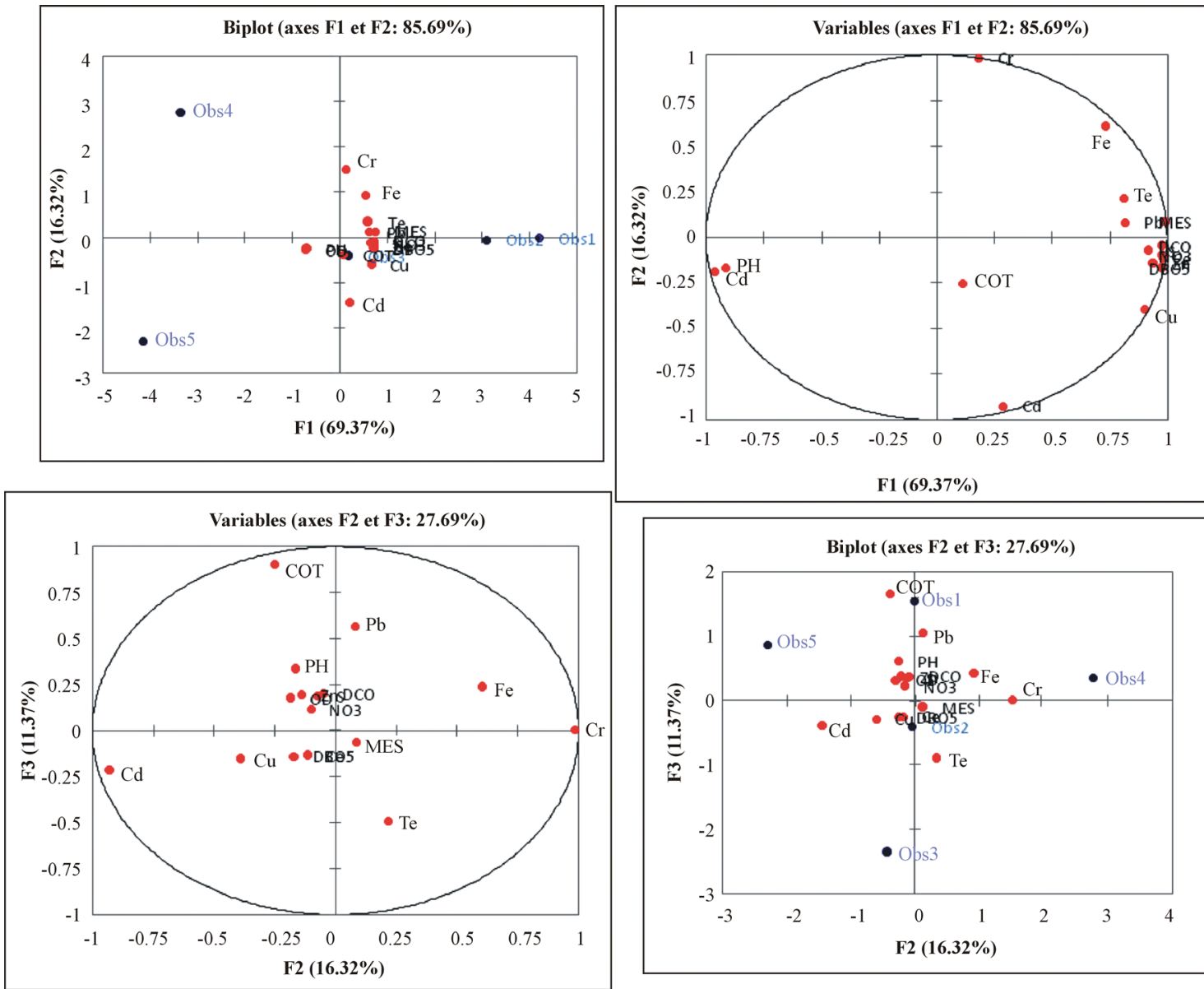

Figure 2. Projections of the physico-chemical parameters and well on the 1-2 plane and the 2-3 plane (during the companions of samples). 
ted in the proximal of the landfill and the river.

Group II: it consists of a single well P3, which is characterized by a relatively high TOC showing water quality deteriorated. This well is located between wells in Group I, it can be regarded as a sink transition.

And for the potential damage of this discharge on the environment and near the site of the dam Oued el Maleh, identifying rehabilitation plan for the latter becomes a necessity [16].

\section{Conclusions}

The examination of the factorial plans will allow to visualize the correlations between variables and to identify the groups of individuals having taken the close values on certain variables. In our study, the variables which contribute most to the axis are also the ones which are the best represented, here we have thirteen parameters which are representative quoting: COD, Ce, Te, Sa, SS, TOC, BOD5, Fe, Zn, Cu, Pb, Cd and Cr.

The analysis allowed us to individualize two major Groups I and II from which we could see the potential damage caused by the discharge of the waters of Wadi el Maleh hence the need to identify a plan adaptable rehabilitation for this landfill.

\section{Acknowledgements}

This work was performed in the laboratory L3GIE of Rabat. The authors thank the anonymous referee for remarks and comments which helped improve the manuscript.

\section{REFERENCES}

[1] A. Serghini, M. Ferkhaoui, A. El abidi, S. El blidi and R. Ben Akkam, "Hydrochemical Characterization of a Ramsar Site: The Wetland Complex of Mohammedia (Morocco)," Bulletin of the Scientific Institute, Rabat, Division of Life Sciences, Vol. 32, No. 2, 2010, pp. 133-145.

[2] A. Boustani, "Solid Waste Managemen Mesbahiat," Ministry of Environment of Mohammedia, 2008.

[3] J. Destombos and A. Jeannet, "Memory Understanding the Geotechnical Map of Meseta Coast East of Casablanca 1/5000 Regions,” Mohammedia Bouznika and Ben Sliman, 1966.

[4] R. El Hamoumi and A. Qninba, "Nesting of Grey Heron Ardea Cinerea Linnaeus, on 1758 (Ciconiiformes, Ardeidae) in Mohammedia (Moroccan Atlantic Coast) 2007 \& 2008," Bulletin of the Scientific Institute, Rabat, Division of Life Sciences, Vol. 30, 2008, pp. 51-52.
[5] R. El Hamoumi, S. Hammada, O. Himmi and M. Fekhaoui, "Form of 'Wetlands of the River el Maleh'. Project to Inscribe New Sites Moroccans on the Ramsar List of Zones Importance of Wet Internationale," WWF International-HCEFLCD—Inst. Sci., Rabat, 2003.

[6] N. Ezzirari, et al., "Impact of Exploitation of Quarries on the Environment and Their Rehabilitations," Journal of Materials and Environmental Science, Vol. 3, No. 4, 2012, pp. 662-669.

[7] A. Noury, "Impacts of Human Activities on Wetlands: The Wetland Area of City of Mohammedia," Memory of Diploma of Higher Depth Study. Mohammed V University, School EMI. Rabat, Vol. 15, 2000, pp. 17-20,31,38.

[8] Rno, "National Network of Observation. Current Program Contaminants in Living Matter, Heavy Metals in Sediments of the Bay of the Seine (Campaign 1993),” Work of the RNO, Ifremer and Minister Planning an Environment, Le Havre, 1995, 36 p.

[9] J. Rodier, “The Analysis of Natural Water, Water Waste," Seawater, 8th Edition, Dénod, 1996, 1383 p.

[10] N. Ezzirari, et al., "Physico-Chemical Characterization of the Landfill of Mohammedia (Morocco),” International Journal of Engineering Research and Applications, Vol. 2, No. 5, 2012, pp. 835-845.

[11] Y. Hamdy and L. Post, "Distribution of Mercury, Trace Organics and Other Heavy Metals in Detroit River Sediment,"Journal of Great Lakes Research, Vol. 11, No. 3, 1985, pp. 353-365. doi:10.1016/S0380-1330(85)71779-0

[12] Y. Sabhi, "Toxicologie des Metaux Lourds chez les Organismes Aquatiques: Aspects Environnementaux et Expérimentaux," Thèse de 3ème Cycle, Mohammed V University Faculty of Science Rabat, 1990, 232 p.

[13] Usepa, "Recommended Protocols for Measuring Trace Metals in Puget Sound Sediments and Tissue Samples," Puget Sound Protocols, Prepared by Tetra Tech inc. for the United States Environmental Protection Agency, 1986.

[14] A. Nicolaidou and J. A. Nott, "Metal in Sediment, Seagrass and Gasteropods near a Nickel Smelter in Greece: Possible Interactions,'Marine Pollution Bulletin, Vol. 36, No. 5, 1998, pp. 360-365. doi:10.1016/S0025-326X(97)00195-1

[15] R. El hamoumi and A. Oninba, "Nesting of Grey Heron Ardea Cinerea Linnaeus, 1758 (Ciconiiformes, Ardeidae) in Mohammedia (Morocco's Atlantic Coast) in 2008," Bulletin 2007 and of the Scientific Institute, Rabat, Life Sciences Division, No. 30, 2008, pp. 51-52.

[16] S. Souabi, K. Touzare, K. Digua, H. Chtioui, F. Khalil and M. Tahiri, "Sorting and Valuation Solid Waste in the Garbage Dump of the City of Mohammedia,” Thesis in Chemistry, Faculty of Science and Technical Chemistry Department Fes, Vol. 6, No. 25, 2011. 